\title{
MIDAS
}

Museus e estudos interdisciplinares

\section{A arte ao serviço do império e das colónias: o contributo de alguns programas expositivos e museológicos para o discurso de legitimação territorial}

Art at the service of the empire and the colonies: the contribution of some exhibition and museum programmes to the discourse of territorial legitimacy

\section{Carla Alferes Pinto}

\section{OpenEdition} Journals

\section{Edição electrónica}

URL: http://journals.openedition.org/midas/957

DOI: $10.4000 /$ midas.957

ISSN: 2182-9543

Editora:

Alice Semedo, Paulo Simões Rodrigues, Pedro Casaleiro, Raquel Henriques da Silva, Ana Carvalho

\section{Refêrencia eletrónica}

Carla Alferes Pinto, «A arte ao serviço do império e das colónias: o contributo de alguns programas expositivos e museológicos para o discurso de legitimação territorial », MIDAS [Online], 6 | 2016, posto online no dia 04 abril 2016, consultado no dia 19 abril 2019. URL : http://journals.openedition.org/ midas/957 ; DOl : 10.4000/midas.957

Este documento foi criado de forma automática no dia 19 Abril 2019.

\section{cc) (†) (2)}

Midas is licensed under a Creative Commons Attribution-NonCommercial-ShareAlike 3.0 International License 


\title{
A arte ao serviço do império e das colónias: o contributo de alguns programas expositivos e museológicos para o discurso de legitimação territorial
}

Art at the service of the empire and the colonies: the contribution of some exhibition and museum programmes to the discourse of territorial legitimacy

\author{
Carla Alferes Pinto
}

\section{NOTA DO EDITOR}

Artigo recebido a 16.01 .2015

Aprovado para publicação a 13.12.2015

1 Em dezembro de 1966 saiu das prensas da editora Excelsior em Lisboa A Arte IndoPortuguesa, a primeira monografia dedicada a este tema desde a sua invenção em 1881 (Pinto 2015). Madalena de Cagigal e Silva (1920-1984), a autora da obra, esclareceu de maneira desassombrada que o termo tinha «servido para designar, com mais ou menos hesitações e restricções, tanto objetos de arte portuguesa com influência indiana, como obras de arte indiana com influência portuguesa» (Silva 1966, 5), remetendo para Sousa Viterbo (1845/46-1910) e John Charles Robinson (1824-1913). O livro de Cagigal e Silva e a definição que nele se dava de indo-português não podiam evitar o equívoco da excessiva ambição do trabalho. Estavam em causa categorias - arte; arte portuguesa; arte indiana que por não terem sido definidas à partida, introduziam fatores de ambiguidade na formulação dos juízos. Igualmente, e não obstante as boas intenções e o imenso trabalho de pesquisa e de troca de informação com outros investigadores, os parcos conhecimentos 
da autora sobre as diferentes expressões artísticas do subcontinente indiano e sobre a arte islâmica condicionavam em muito as possibilidades interpretativas do texto.

Surgido num contexto de afirmação nacionalista face aos acontecimentos de carácter político e diplomático que circunstanciaram a publicação do livro, a reconfiguração do indo-português em categoria artística (isto é, substantivando o termo que era utilizado para classificar um objeto artístico), foi o corolário de um processo de afirmação de Portugal através da narrativa que associava a ideia da "heroica gesta descobridora dos Portugueses" ao objeto artístico. De alguma forma, Cagigal e Silva reunia num único volume programático, o conjunto de contributos que os guiões museológicos e expositivos nacionais haviam desenvolvido, tornando-o uma mera etapa num percurso que se foi construindo desde 1882 e se prolongou bem para além da década de 1960.

3 Neste texto procurarei fundamentar esta argumentação, analisando alguns episódios relacionados com a história do Museu Nacional de Arte Antiga (doravante MNAA) e a programação expositiva internacional que compassou esta realidade.

\section{Os antecedentes históricos}

4 O termo indo-português surgiu no domínio da dialetologia no final da década de 1870 , simultaneamente em Portugal e na Alemanha (Pinto 2015). Em 1881 seria pela primeira vez empregue na classificação de objetos artísticos (categorizados como artes decorativas) por John Charles Robinson na Special Loan Exhibition of Spanish and Portuguese Ornamental Art, apresentada no South Kensington Museum (hoje, Victoria \& Albert Museum, Londres). Foi depois comentado, utilizado e criticado por Sousa Viterbo nas também celebradas Notas ao Catalogo da Exposição Retrospetiva de Arte Ornamental Portuguesa e Espanhola realizada no Museu de Belas-Artes em Lisboa (atual MNAA) em 1882 (Viterbo 1883).

5 Firmemente ancorado num entendimento de carácter étnico e nacionalista, o indoportuguês, cujas propostas de definição foram sempre algo ambíguas, serviu a intenção memorialista de matriz imperial desde a sua criação (Pinto 2015). Todavia, a receção dos móveis, têxteis e ourivesaria indo-portuguesas (ou seja, os tipos que foram englobadas nesta caracterização) não fora unânime nem continuada, e, sobretudo, vira-se envolvida nas polémicas de final de Oitocentos em torno quer da formação (ensino) e constituição de um campo científico de história da arte em Portugal quer de defesa de uma arte nacional (Baião 2014), na qual havia pouco lugar para qualquer expressão diferenciadora (mesmo que étnica).

6 Estas polémicas também serviram de cenário à criação do museu nacional (Gomes e Vasconcelos 1883, 44; Leandro 1997, 55), já que havia que «relembrar que os propósitos da organização de Lisboa não eram, realmente, as indústrias caseiras (...), mas as produções que ilustravam a sumptuosidade de uma herança patrimonial nacional» (Ferreira 2010, 343). 0 que, aliado às críticas, condicionou inelutavelmente os programas expositivos do futuro MNAA. A valorização do passado (heróico ou não), em detrimento de uma reflexão sobre um futuro expresso através dos valores da industrialização (formação, produção e comercialização), entrava em força no discurso e programa expositivos.

7 Ainda assim, na elaboração das equipas de conservadores/as e das coleções do museu, o indo-português não fora esquecido, mesmo que não tivesse cariz de autonomia que lhe desse foros de espaço específico. Foi neste contexto que a formação de figuras como Luís 
Keil (1881-1947), um historiador de arte que tem sido pouco estudado no panorama da historiografia nacional e que merece uma redobrada atenção, e Cagigal e Silva, no âmbito do estudo das artes produzidas em contextos não-europeus, fez, desde sempre, parte das preocupações dos diretores, dos/as técnicos/as na programação museológica e da estratégia de atuação do MNAA. ${ }^{1}$

8 A primeira exposição organizada no museu dedicada ao indo-português data de 1938 e, não estranhamente, foi sobre mobiliário. 1938 também foi o ano da nomeação de João Couto (1892-1968) para a direção do museu e aquela foi a segunda exposição temporária da sua programação. Couto inaugurava uma fase, criava um novo campo de trabalho e autonomizava o indo-português na narrativa museológica, ainda que tal refletisse a continuidade estratégica que vinha de José de Figueiredo (1872-1937). O mobiliário, os têxteis e a ourivesaria que a exposição de arte ornamental de 1882 colocara no âmbito do indo-português tinham foros de consagração no museu nacional. Faltava a escultura, que se mantinha alheada dos projetos museológicos e expositivos.

Os marfins indo-portugueses surgiriam, assim nomeados, num contexto que só poderia advir da reflexão em museu, suscitada pela preparação de uma mostra de carácter iconográfico: o Natal. Porém, tanto o museu quanto a Liga Independente Feminina Diocesana (corresponsável pela exposição), propunham-se «apresentar alguns aspectos do NATAL nas várias modalidades da Arte Portuguesa» (7.․ㅗ Exposição Temporária 1947, vii), abreviando a capacidade expressiva daqueles objetos à sua essencialidade portuguesa.

Em 1947 Cagigal e Silva já se encontrava no museu. Com efeito, estava desde outubro do ano anterior a elaborar o inventário das gravuras provenientes da Biblioteca Nacional de Lisboa, pelo que será difícil perceber o alcance da sua possível colaboração na preparação e montagem desta exposição. Mas em 1949 apresentava, como trabalho de bolseira ao Instituto de Alta Cultura, o texto «Alguns Aspectos Decorativos Orientais na Arte Indoportuguesa» que, não por acaso, vinha na sequência dos trabalhos desenvolvidos por Luís Keil, que morrera tragicamente no ano de 1947. Ou seja, é muito provável que Cagigal e Silva tivesse beneficiado do convívio e ensinamentos de Keil (nos cerca de 12 meses em que partilharam o espaço) e que o próprio museu, isto é, João Couto, depois do desaparecimento de Keil, tivesse selecionado Cagigal e Silva para continuar a tarefa que aquele encetara. Em suma, apesar do indo-português não se emancipar na programação, havia uma estratégia de estudo continuado por parte dos/as conservadores/as do MNAA.

11 Paralelamente, Portugal fazia-se representar no circuito expositivo internacional, já no rescaldo da Exposição Retrospectiva de Arte Ornamental Portuguesa e Espanhola (Lisboa) e da Exposição Distrital de Aveiro, ambas realizadas em 1882.

\section{A Exposição Colombina, Madrid, 1892}

12 No dia 5 de novembro de 1891, a assembleia geral da Academia Real das Ciências decidiu a participação portuguesa na exposição destinada a comemorar o quarto centenário da chegada de Cristóvão Colombo à América. Assente, desde o início, tratar-se de uma exposição histórica, considerou-se que era «um dever nacional concorrer áquella grande festividade, não só para corresponder a tão honroso convite da nação vizinha, mas tambem para afirmar a parte gloriosa que tiveram nossos maiores na descoberta do novo mundo» (Araújo 1892, 4-5). 
13 Depois de atribuído o subsídio e pensado o programa, ficou decidido que a exposição se dividiria em quatro secções: marítima, documental e bibliográfica, de etnografia americana e de arte ornamental. O programa português dividia-se em três grandes propósitos: o apologético (no qual se inclui as secções I e II), o etnográfico, do qual se excluíam, portanto, as formas artísticas vindas de geografias não-europeias, e a arte, nomeada como ornamental, mas, como se vai ver, nem por isso isenta de equívocos.

14 A classificação das peças era feita de forma algo arbitrária, já que sob a letra $\mathrm{A}$ se escolhiam os espécimes de ourivesaria portuguesa do século XVI, provenientes de coleções públicas e privadas; sob a B encontravam-se os móveis portugueses de inspiração indiana, as tapeçarias, etc.; na C: «Photographias dos principaes monumentos portugueses, egrejas, túmulos, pelourinhos, etc., da epocha manuelina e mais importantes detalhes da architectura da referida epocha, destinados a exemplificar a originalidade do estilo português e a suas diferenças características do pleteresco hespanhol», e na D: coleções de livros, iluminuras, encadernações, etc., genericamente designadas por "bibliografia artística" (Araújo 1892, 11-14). Todavia, na descriminação das peças constava mais de um exemplar de pintura em madeira (por exemplo, da sacristia do convento da Madre de Deus).

Portugal iniciava oficialmente o programa das representações internacionais com base na ideia da glorificação das "descobertas" e dos "descobrimentos portugueses". o programa caminhava para a construção da ideia da heroicização dos descobrimentos e seus agentes (Roque 2001, 43), e de redescoberta das colónias, no que elas tinham de valorização de e para Portugal - incluindo a vertente religiosa, que aflorava aqui pela primeira vez - e não no seu potencial intrínseco.

16 É sintomático que as últimas páginas do opúsculo de Araújo (1892) sejam dedicadas à descoberta recente de uma imagem-documento que ainda hoje consta de todos os programas comemorativos da expansão portuguesa: o célebre mapa dito de Cantino. Identificado pela Sociedade de Geografia Italiana de Roma, fora fotografado e enviado ao Ministério dos Negócios Estrangeiros (que o remetera para a Comissão), junto com um documento de 19 de novembro de 1502, que contava a história da cópia do mapa. Para além deste, a Comissão enviava a Madrid uma série de outros, alguns em fac-simile, inaugurando uma longa tradição de incluir mapas nas exposições de arte, com a dupla valência de objeto artístico em si e de imagem-documento que atestava a primazia portuguesa no espaço que cartografavam.

\section{A Exposição Ibero-Americana, Sevilha, 1929}

Apesar dos anos de diferença e da mudança de regime (19 anos após a implantação da República), a Exposição Ibero-Americana de Sevilha seria o retomar do propósito de heroicização (numa nebulosa entre o confronto e o paralelismo) dos impérios ibéricos, perdidas que estavam as tentativas de manutenção a par com as potências europeias dominantes.

No Guia Oficial (1929), a representação portuguesa explicava a organização e os fins da exposição. Para além deste, foi publicado um catálogo que refletia a programação e tinha um texto de José de Figueiredo. Nas palavras do diretor do MNAA:

Esta exposição não [era] organizada para mostrar o valor da Arte portuguesa na época dos nossos Descobrimentos e Conquistas. O seu objectivo [era] mais restrito. 
Limita[va]-se a um único aspecto, embora dos mais importantes da nossa cultura artística nesse período, ou seja o reflexo que os Descobrimentos e Conquistas trouxeram à Arte portuguesa de então, e, por sua vez, a projecção que esta teve nos territórios que conquistámos, e onde a sua influência se afirmou desde a África do Norte até à Índia, para, de lá, atingir, com a China e o Japão, o mais remoto Oriente. (Figueiredo 1929, 5)

Criava-se um novo paradigma. o primado era o da "arte portuguesa", o tema maior em que se inseria aquilo que Figueiredo propunha como dos mais importantes aspetos da cultura artística daquele período: por um lado, as consequências para a arte portuguesa dos descobrimentos - isto é, do que tendo sido visto lá fora pudesse ter sido incorporado nas formas nacionais -, por outro, a projeção que a arte portuguesa tinha tido nos territórios conquistados, desde o norte de África até ao remoto Oriente (ou seja, a Ásia Oriental). Neste domínio, Figueiredo abriu o campo espacial como nunca, associando todas as geografias a um mesmo movimento. Ou seja, alargando o campo do que se poderá designar por arte colonial para além do indo-português.

20 A formulação de uma "arte portuguesa" permitiu, a um tempo, integrar os objetos artísticos coloniais numa genealogia de formas e motivos europeus (as técnicas são bem outra coisa). Mas, a outro, levou a que o país se abstivesse (quase sempre) de procurar contextualizar, conhecer, criar coleções, fundamentar relações sociais e culturais, enfim, estudar e interpretar formal e historicamente qualquer outra das nações que se cruzaram com o Portugal dos "descobrimentos e conquistas", motivado quer pela anacronia do pressuposto epistemológico quer pelo cerrar de fileiras em torno da «primazia, ancestralidade e excepcionalidade» colonizadora portuguesa. Esta aparente relação que de facto evocava outros espaços era afinal unidirecional, ainda que Figueiredo achasse o indo-português uma arte mista. Mas qual era o programa de Figueiredo? Nas palavras do seu autor, era:

[...] pela primeira vez juntar aos painéis de Nuno Gonçalves as tapeçarias feitas sôbre cartões seus, constituindo assim, embora temporàriamente, um prodigioso políptico em que a acção e a contemplação mística se irmanam e dão as mãos, alguma coisa contudo fica de fora que caberia também o melhor possível aqui. Refiro-me aos biombos japoneses, comemorativos da chegada dos portugueses à terra nipónica em 1542, facto que marcou e marca ainda época nessa nação. E, com os biombos, os selins de laca do século XVI, e as pinturas e estatuetas de marfim, e as gravuras e demais provas da nossa influência cultural nesse país, que ilustres historiadores da Universidade de Toquio reconheceram ter atingido até a própria epigrafia.

E, deixando o Japão pela Pérsia, poderíamos igualmente expor, ao lado da imagem iluminada de senhora nobre do século XVI, que aqui trouxemos e provém do museu de Lisboa, o retrato, também iluminado, do jovem fidalgo do mesmo século, da colecção Doucet, de Paris, e ainda os tapetes quinhentistas dos museus de Lião e Viena, em que se verifica mais uma vez a influência portuguesa, (...). E, depois, sem esquecer a China e sobretudo a Índia, onde demos origem à formação de uma arte mixta, característica, a chamada arte indo-portuguesa, seria preciso mostrar também, com o panorama da cidade de Gondar, edificada na Abissínia pelos portugueses, no século XVI, as outras provas da nossa influência cultural nesse país. Ao lado de tudo isso, caberiam, por sua vez, as fotografias e desenhos do que da nossa actividade artística subsiste ainda um pouco por todo o mundo, dêsde Marrocos até Malaca, e outras ainda mais longínquas regiões. Tudo isto excederia porém o fito a que visamos e a capacidade de espaço de que dispomos.

E por isso e porque entendemos que uma exposição como esta deve ser antes santuário de relíquias veneráveis do que mero repositório para ensinamento doutrinário, pusemos de parte todos esses elementos, convencidos de que as 
reproduções e fac-similes de pouco ou nada valeriam aqui. Quando se trata de evocações - e foi para esta jornada espiritual que sobretudo aqui viemos - só a peça autêntica tem poder para tal milagre. (...)

Com sacrifício, que reveste certo heroismo, entendemos portanto dever trazer aqui, com os painéis de Nuno Gonçalves - o maior tesouro artístico que possuimos - a custódia de Gil Vicente, o atlas de Vaz Dourado, a carta de Caminha e a do mestre João, e autógrafos de Vasco da Gama e dos outros grandes capitães da Índia e, entre êstes, um do maior de todos êsses capitães, o famoso e «Terribil» Afonso de Albuquerque, figura tão excepcional de guerreiro e político como Alexandre, César e Napoleão. E fizemos isto, porque todo o passado glorioso e longínquo, que êsses homens e obras de arte representam, só desta maneira poderia ser completamente sentido. E para êsse feito não será necessário grande esfôrço, pois bastará que os que param diante dessas relíquias as queiram e saibam interrogar. (Figueiredo 1929, 5-8)

21 Figueiredo reproduzia valores inerentes à sua prática de diretor do MNAA: defendia a mostra do original em detrimento da cópia ou do fac-simile e propiciava discursos e leituras para os visitantes da exposição, nas quais se inseria, precisamente, a produção de um catálogo. Fora assim que, não obstante o seu ambicioso plano teórico e face à escassez das coleções nacionais, se vira na contingência de levar a Sevilha as relíquias nacionais, que exprimiam todo o passado glorioso e longínquo uma vez que aquela era uma jornada espiritual.

Em Sevilha o que encontramos é a representação (Chartier 1988) do império dentro de uma dinâmica de valorização da arte portuguesa (que se refletia, também, nos espaços coloniais) e não apresentação, nomeadamente porque a única peça colonial mostrada na sala mais emblemática era uma mesa indo-portuguesa (a tal "arte mista" que, contudo, deixa as estatuetas de marfim de fora). O que é ainda mais interessante de constatar nesta sala é que, recorrendo a peças exclusivamente europeias, glorificava a ideia dos "descobrimentos" e da influência artística e cultural portuguesa no mundo, socorrendose das tapeçarias da conquista de Arzila por D. Afonso V, dos painéis de Nuno Gonçalves, de alguma da melhor pintura de cavalete da coleção do MNAA e da icónica Custódia de Belém.

23 A importância que o país dava à participação na Exposição Ibero-Americana pode ser, também, medida pelo registo memorialista em imagem que dela foi feita. Para além das fotografias sevilhanas, no catálogo publicaram-se 44 reproduções em papel couche a preto e branco, todas reportando para as salas do MNAA, onde as peças indo-portuguesas se integravam no percurso regular da "arte portuguesa".

\section{A Exposição Colonial de Paris, 1931}

Portugal apresentou-se nesta mostra com quatro pavilhões, dirigidos e planeados pelos melhores técnicos que havia no país, Henrique Galvão (1895-1970), Raul Lino (1879-1974) e Figueiredo. Publicou também vários textos em francês, que ajudavam a consolidar a ideia de Portugal como potência colonial (Bethencourt 1999, 469-470).

A exposição de arte inseria-se no programa geral. Comissariada por José de Figueiredo e por André Dezarrois, conservador de Écoles Étrangères Contemporaines no Museu Jeu de Paume, mostrou-se nesse museu e não no bosque de Vincennes, onde o circo colonial estava montado. 
26 A Exposição Colonial de Paris não foi o sucesso inequívoco que a França esperava. Em plena realização do evento, o partido Comunista, os Surrealistas, os estudantes e os expatriados dos países "retratados" no evento faziam-se ouvir como nunca antes, concentrando na Contra-Exposição Colonial as vozes que se opunham a tal demonstração. Mas o novel Portugal salazarista não parecia assustado com tais esquisitices. A exposição colonial portuense realizar-se-ia em 1934 e o culminar da comemoração de todos os centenários nacionais foi festejado com a Exposição do Mundo Português em 1940, também ela adornada com um heterogéneo «zoológico humano» colonial português (Bethencourt 1999, 462-464).

O pensamento, a escrita e a ação de Figueiredo serviram que nem uma luva à narrativa centrada no grande Portugal colonial, tão em voga na altura. Começava aqui a operar-se uma subtil variação na narrativa, já que partindo da primazia inquestionável do objeto artístico como princípio fundador do discurso expositivo, este acabava por servir de forma mais eficaz e uníssona à prática colonial. Em suma, a "arte portuguesa" transformava-se em veículo de afirmação da prioridade e inegável autoridade do Portugal colonial.

O programa do diretor do MNAA vingara de tal maneira que o texto introdutório ao catálogo da exposição de 1931 foi uma quase tradução para francês do que se publicara em Sevilha. As alterações são tímidas, mas de estridente reflexo quanto ao que em dois anos a visão de Figueiredo, e conformação ao programa do Estado Novo, conforme a Constituição de 1933, se redimensionara. O texto merece atenção. A propósito da sua proposta de juntar os painéis de Nuno Gonçalves com os biombos japoneses, mantendo a mesma ideia de "acção e contemplação mística", Figueiredo escrevia em francês:

[...] nous n'en devons pas moins [que à Espanha, a propósito da deslocação das tapeçarias da tomada de Arzila para Sevilha] à la France. Elle nous a fait, avec d'autres prêts magnifiques, et celui du lieu même de notre exposition, le précieux prêt d'un de ces paravents japonais, qui rappellent l'arrivée des Portugais sur la terre du Nippon, en 1542. (Figueiredo 1931, 7).

O programa sevilhano concretizava-se em Paris através da introdução, finalmente, de um biombo japonês (Musée Nationale des Arts Asiatique/Guimet, Paris, MG18653). Igualmente, o catálogo complexificara-se. Acrescentara-se-lhe mais três capítulos e reinterpretara-se os dedicados à pintura e aos móveis e têxteis. Um dos três capítulos retomava a memória da exposição de Madrid em 1892, através dos «manuscritos, livros impressos e miniaturas, portulanos» e "peças orientais com influência portuguesa».

o capítulo da pintura é o único em que é visível uma concessão ao que seria o propósito do comissário francês, conservador no Museu Jeu de Paume das «escolas estrangeiras contemporâneas», ou seja, da pintura coeva não francesa. Figueiredo levou a Paris Columbano Bordalo Pinheiro, mas também, Vieira Portuense, Domingos Sequeira, Tomás da Anunciação, Miguel Ângelo Lupi e António de Silva Porto.

31 De resto, tudo é um programa histórico e de glorificação do que de melhor havia em Portugal. Nem por acaso, o texto dedicado à cerâmica começava: «Ce ne fut qu'après notre arrivée par voie de mer en Chine, en 1510, que les porcelaines, ainsi que les autres produits manufacturés de ce pays, ont cessé d'être considérés en Europe comme des raretés» (Figueiredo 1931, 57). E só depois se mencionava o apreço que a cerâmica sempre merecera aos portugueses, remontando a encomenda estrangeira de excelência aos Della Robbia. 

hesitações houvesse sobre como a cedência de Figueiredo a um programa ideológico é visível nesta narração aparentemente tão semelhante à de 1929, veja-se a forma como integrou a iluminura que estivera em Sevilha (e em cujo catálogo se ligara à pintura) na mostra de Paris: «A côté de la peinture, c'est peut-être l'enluminure qui a, au Portugal, le plus accusé l'influence de la mer et de l'Oriente» (Figueiredo 1931, 63). Esta frase excessiva potencia duas vertentes de análise imediatas. Por um lado, a constatação de que os objetos artísticos se rendiam a uma doutrina político-ideológica que levou Figueiredo a cometer (os muito pouco comuns) erros: a chegada dos portugueses à costa do sul da China não data de 1510 (que é antes a da conquista de Goa por Afonso de Albuquerque) mas, na melhor das hipóteses, de 1513, através de esporádicos contactos e não de instalação; e, mais que a pintura, as artes portáteis revelavam intensamente a influência asiática. Por outro lado, a perceção de que a cartografia mostrava uma componente estética que tinha que ser valorizada; e nisto, o diretor do MNAA era profundamente inovador.

Voltando às informações contidas no catálogo, seguiu-se à cerâmica e à cartografia, o capítulo dos móveis e bordados. Figueiredo começou-o de maneira empolada:

Un des faits relatifs à nos Découvertes et Conquêtes qui nous intéresse particulièrement ici, c'est le souci d'art qu'on trouve chez tous nos grands marins et guerriers de cette période et qui s'explique facilement quand on connaît le haut degré de notre culture à cette époque et l'on sait aussi que ces hommes sortaient en général de l'élite du pays. (Figueiredo 1931, 71)

A arte era, assim, o reflexo dos «homens guerreiros e marinheiros», saídos das elites culturais e sociais do país (nova imprecisão do diretor do MNAA), e que, depois de erguerem fortalezas, debuxarem igrejas e iluminarem os portulanos, «explique[nt] la naissance et le développement de cet art hybride et typique, l'art indo-portugais d'où sortent - exemples caractéristiques - quelques-unes des pièces de mobilier que nous avons apportées à notre exposition» (Figueiredo 1931, 71).

O diretor do MNAA não parecia ter hesitações sobre a definição do conceito de indoportuguês (a grande arte portuguesa transportada a par de guerreiros e marinheiros e produzida no império) e que se consolidava como discurso museológico. Ao colar híbrido e típico, Figueiredo incorria definitivamente na doutrina rácica e progressista do Congresso Colonial de Paris que decorreu concomitantemente à exposição, e do pensamento de Henrique Galvão.

Figueiredo seguiu alertando para a maior extensão da influência portuguesa, que chegara a costas do Japão. De novo, ainda que exagerada, a sua posição era visionária ao préanunciar a existência de uma escola de pintura jesuíta nipónica:

Ceux-ci [os japoneses], élevés par les Jésuites portugais, sont probablement les auteurs de plusieurs œuvres d'art dont le caractère tout particulier est loin d'être bien éclairé. Tel est le cas du portrait enluminure de notre grand poète Camoëns, fait à Goa en 1589, que nous avons publié dans les Lusiades édités par les soins du Prof. Doct. José Maria Rodrigues et du poète Afonso Lopes Vieira. (Figueiredo 1931, 71)

E, finalmente, o biombo do Museu Guimet: «Paravent japonais représentant l'arrivée, en septembre 1551, au Japon prés du port de Funai (Bungo), de la nef commandée par Duarte de Gama et la rencontre de celui-ci et du célèbre voyageur Fernão Mendes Pinto avec saint François-Xavier» (Figueiredo 1931, 75). 
$38 \mathrm{Na}$ extensa entrada de catálogo que escreveu, Figueiredo fez várias apreciações que mostram como estava a par do que se publicava e como estava atento aos estudos sobre a arte japonesa (dos biombos em particular), mas, também, de como deixara, como nunca antes, que o objeto e o conhecimento que tinha sobre arte se submetessem ao programa ideológico: quer a legenda quer o texto da entrada do biombo incorporam mais imaginação dirigida para um propósito do que a realidade. Não há nada no biombo do Museu Guimet (como em nenhum outro) que reporte para um momento específico da presença dos portugueses no Japão (Campos 2007, 145-233). O arrojo em nomear, datar, classificar e descrever o episódio do encontro de Fernão Mendes Pinto com S. Francisco Xavier cai tanto no domínio da lenda que era atribuída à escrita do primeiro, quanto revela da ausência dos referentes metodológicos de Figueiredo. A religião entrava sem hesitações no desígnio imperial novecentista. Heróis e missionários tinham encontrado a sua expressão na arte.

O que subjaz do que ficou escrito resume-se a um ponto fundamental que se relaciona com a maneira como a arte colonial (na qual se incluía o indo-português) se autonomizou do propósito etnográfico, através de uma valorização do objeto artístico que, por razões inerentes à constituição da própria disciplina da história da arte, foi englobada numa narrativa de construção da arte portuguesa. E como, por isso mesmo, o termo indoportuguês entrou nos programas museológicos e expositivos de afirmação da arte portuguesa na Europa, para depois se transformar no mais demonstrativo dos dispositivos de primazia colonial do país.

\section{A Exposição de Arte Portuguesa, 800-1800, Londres, 1955-1956}

40 O programa expositivo (e museológico) de Figueiredo evoluíra com o propósito de fundamentação histórica da política colonial do regime. E se, como argumento, haveria uma continuidade narrativa entre este discurso e a direcção de João Couto (que os textos deste não desmentem), porque razão não foi ele o comissário da grande exposição internacional de arte portuguesa do Estado Novo?

41 A razão reside numa ardilosa alteração da imagem de Portugal e dos agentes nela envolvida (Acciaiuoli 1991, 51). Isto é, o que em 1931 era um discurso justificativo de uma doutrina política colonial mas inserido, ainda assim, numa mostra entre pares, foi, em 1956, uma anacrónica exibição de um império em estertor, uma ação de propaganda, tanto mais acentuado quanto continuava a assentar em demonstrações de "direito histórico", já que não foi por acaso que a cartografia e as fotografias voltariam a estar presentes na justificação da afirmação territorial e imperial portuguesa.

Com efeito, a exposição londrina de 1955 inseria-se no movimento de «actualização do imaginário imperial» levado a cabo pelo Estado Novo e que estava colocado à imagem do regime (Bethencourt 1999, 462). E, desta forma, o objeto artístico passava a ser veículo (entre outros: algumas salas foram destinadas à exibição de fotografias de monumentos históricos e arquitetura coeva portuguesa) de uma mensagem elaborada noutros círculos de poder não museológicos, dispensando por isso o diretor do MNAA como comissário (Fernandes 2001, 14). De igual modo, a realização desta mostra não pode de forma alguma ser dissociada do contexto político-diplomático de pré-guerra colonial que a originou, nem do pensamento de quem a gizou, Reinaldo dos Santos (1880-1970). 
43 A questão do império era, desde final do século XIX, um problema que dividia Portugal da restante Europa, com destaque para a Inglaterra e a Alemanha. Para além dos resultados frustrantes da Conferência de Berlim (1884), da humilhação do Ultimato Inglês (1890) e das dúvidas europeias sobre a capacidade colonizadora de Portugal, o Estado Novo lidava então com problemas bem mais graves, desde que a Inglaterra concedera a independência à Índia, a 15 de agosto de 1947.

44 A Índia Portuguesa estava rodeada pelo ímpeto e fulgor de um país em formação que não se coadunavam com o enclave "católico" e economicamente pouco desenvolvido de Goa. A acrescentar a esta preocupação, havia o facto de Portugal ter sido recentemente aceite como membro da Organização das Nações Unidas (1955), inserido num pacote de adesões negociada entre as duas potências dominantes - Estados Unidos e União das Repúblicas Socialistas Soviéticas -, o que não invalidava a antipatia que o regime e a sua política colonial suscitavam junto de alguns países-membros e, inclusive, o início de um paulatino cerco anticolonialista (Fernandes 2001, 262-279; Martins 1998).

Assim, esta exposição surgira como a possibilidade de usar um palco internacional e prestigiante para exercer o que chamaríamos hoje uma "política de charme", em que a arte e a legislação manuelina e filipina justificariam o império português. Nas palavras do comissário, a aceitação do convite devia-se ao «prestígio cultural e artístico do País, àparte a significação política, que me não cumpre julgar» (Fernandes 2001, 37, 42-43). Reinaldo dos Santos era o homem escolhido para o papel.

A João Couto caberia um papel como membro da comissão. Tal como a Mário Tavares Chicó (1905-1966), então diretor do Museu de Évora («as únicas presenças relevantes no campo da museologia e da História da Arte»), que contribuiria apenas com a cedência e a organização de fotografias de arquitetura (que estavam intimamente ligadas à missão à Índia realizada sob patrocínio do Ministério da Educação Nacional, Ultramar e Obras Públicas) (Fernandes 2001, 37, 42-43 e 208; Azevedo s/d).

Aberta ao público entre outubro de 1955 e Fevereiro de 1956, mostrava, afinal, o quê e sob que programa? A proposta era de uma mostra «mista, isto é dos vários aspetos da Arte portuguesa não só, das artes maiores como das decorativas», ou seja, em abstrato, tudo, correndo 1000 anos de história (de 800 a 1800). Revelando alguns embaraços na concretização do evento, apenas um dos sete textos fundamentais para perceber o pensamento do comissário no gizar da mostra foi escrito antes da realização da mesma. Trata-se do ofício dirigido ao Ministro da Educação Nacional, já que os restantes seis (elaborados para acompanhar a exposição ou depois de concluída, e que incluem as versões do catálogo em inglês e português ou artigos para revistas especializadas e jornais de grande circulação). «São textos com níveis de formulação diversos, por vezes aparentemente desajustados dos seus objetivos, vagos quando deviam ser precisos, poéticos quando deviam ser esquemáticos, extensos quando ganhavam pela síntese». Contudo, Reinaldo dos Santos não revelara hesitações. E é fácil perceber porquê, já que esta exposição era o culminar, aos 76 anos, do projeto de uma vida: o estudo da arte portuguesa subordinada à ideia de «unidade de espírito e sentimento» que lhe conferiam a originalidade (Fernandes 2001, 64, 63 e 66).

$\mathrm{O}$ indo-português, e a arte colonial em geral, tinham tido entrada precoce no discurso de Reinaldo dos Santos, acentuada por dois acontecimentos ocorridos em 1954: a sua viagem à Índia e a publicação do artigo "A Índia Portuguesa e as Artes Decorativas». Chegado de Goa havia um escasso mês, no dia 29 de Abril de 1954, Reinaldo dos Santos proferira uma 
conferência no Secretariado Nacional de Informação que começava de uma maneira que nos remete evocativamente para o programa da exposição:

Não posso iniciar uma conferência sobre Goa, donde acabo de chegar há alguns dias, sem que as minhas primeiras palavras sejam de homenagem ao Senhor Presidente do Conselho Doutor Oliveira Salazar que, com tanta elevação defendeu os direitos históricos, jurídicos e culturais, que integraram desde há quatro séculos e meio a Índia Portuguesa na comunidade Nacional. (Santos 1954, 3) marcaria também o início do desmoronar da presença portuguesa na Índia com a perda dos territórios indianos de Dadrá e Nagar-Haveli (Guzerate). Na conferência feita em abril, Reinaldo dos Santos confessara o propósito de estudar as artes decorativas da Índia portuguesa que, «a par das artes maiores, nos revela[va]m a importância da nossa acção espiritual não só no domínio religioso e social, que é o melhor conhecido, mas no domínio das artes que é ainda hoje o menos bem estudado» (Santos 1954, 4). Aliadas à narrativa nacionalista e religiosa, as artes decorativas faziam a sua entrada no discurso oficial de um Portugal indivisível metropolitano e ultramarino. Todavia, a realidade revelar-se-ia mais disruptiva. 1961 marcou o início da Guerra Colonial em África e o fim da administração portuguesa sobre os territórios indianos.

Cinco anos mais tarde, Cagigal e Silva inventava a arte indo-portuguesa e, ao fazê-lo, criava um problema. É que ao inventar uma arte indo-portuguesa - «"Estilo", no sentido artístico, será tudo quanto caracteriza e individualiza uma obra de arte ou um grupo de obras de arte» -, Cagigal e Silva tinha que desenvolver um sistema de classificação que apurasse características mais ou menos constantes, repetitivas e comuns a todos os objetos, o que seria manifestamente difícil. Por isso, o livro dividia-se em partes com capítulos sobre materiais, formas, decoração (o mais extenso de todos), origem e evolução, e, dentro destas, organizava-se em tipologias, tentando relacionar toda a informação recolhida. E o «inegável estilo indo-português» era-o porque as «peças indo- 
portuguesas são diferentes das obras de arte indiana e diferentes também das obras de arte portuguesa» (Silva 1966, 359).

Muito do material iconográfico utilizado no mesmo, como fotografias, desenhos, etc., e algo do que ficou escrito, era devedor da já mencionada missão à Índia de 1951 (realizada por Mário Tavares Chicó, Carlos de Azevedo, Humberto Reis e pelo fotógrafo José Carvalho Henriques).

Sabendo que a missão de 1951 tinha óbvios propósitos políticos de mapeamento e classificação de um território arquitetónica e urbanisticamente "português" na Índia, por que razão mediou uma década entre a viagem e o texto? E, ainda, por que razão foi o trabalho confiado (e foi confiado ou foi proposto pela autora) a Cagigal e Silva (na altura conservadora do Museu de Arte Popular) e não a algum conservador/a do MNAA? Muito possivelmente porque este se tratava de um projeto pessoal que constituíra a «maior entrega» da vida da autora e porque, na realidade, a publicação da obra se arrastou durante tempo considerável (Gomes 1964, 2).

Como atrás vimos, incluída numa estratégia definida pelo MNAA ou não, Cagigal e Silva revelara desde cedo interesse pelo estudo da relação artística entre Portugal e a Ásia e, não obstante as inúmeras adversidades da sua vida, era munida de uma tenacidade e capacidade de trabalho que lhe mereceu notável reconhecimento em vida. O longo percurso nos museus poderá ter acabado por resultar em seu desfavor. Com efeito, Cagigal e Silva foi formada num ambiente que alimentou a narrativa da especificidade da arte portuguesa que conferia autenticidade ao indo-português, e a que correspondia também uma visão feliz e harmoniosa daquele período histórico.

O seu derradeiro contributo foi a comunicação que apresentou ao II Seminário Internacional de História Indo-Portuguesa, realizado na Torre do Tombo em Lisboa em 1980 e ao qual compareceu já doente. Nas palavras que proferiu era audível um certo desalento, uma postura algo defensiva e uma tentativa frustrada de atualizar a informação e as interpretações que entretanto deverá ter colhido no contacto com os/as colegas que encontrou no Seminário (Silva 1985).

A atávica desatualização na interpretação que o nome de Cagigal e Silva conferia ao indoportuguês, aliado à inevitável colagem a um tempo político que se queria esquecer, contribuem para justificar o total esquecimento a que esta conservadora foi votada.

$\mathrm{Na}$ realidade, e ainda que solidamente fundamentada no conhecimento técnico, pese embora as interpretações exageradas e abusivas, designadamente na identificação e leitura dos significados da presença de personagens da mitologia e religião hindu, budista, islâmica nos objetos indo-portugueses, o posicionamento discursivo de Cagigal e Silva não fugia à narrativa etnicista que, desde início, enformou a conceção do indo-português, aqui e ali fortemente eivada de pendor nacionalista. O que, como se viu, tinha raízes profundas, e que se prolongaram até final do século XX. E não era discurso solitário, já que muitos outros/as autores/as ajudaram a consolidar esta narrativa (Pinto 2014, 197-245). Nomes como os de Luís Keil, Bernardo Ferrão ou Reinaldo dos Santos, cujos percursos profissionais e textos urge revisitar. 


\section{BIBLIOGRAFIA}

7. Exposição Temporária: Aspectos do Natal na Arte Portuguesa. Catálogo. [1947]. Lisboa: Museu Nacional de Arte Antiga.

Acciaiuoli, Margarida. 1991. “Os Anos 40 em Portugal: O País, o Regime e as Artes, "Restauração" e "Celebração". Tese de doutoramento em História da Arte Contemporânea, Universidade Nova de Lisboa.

Araújo, Joaquim de. 1892. A Commissão Portuguesa da Exposição Colombina. Lisboa: Typographia da Academia Real das Sciências.

Azevedo, Carlos. s/d. Mário Chicó e a Índia. Consultado em janeiro 15, 2015. http:// www.fmsoares.pt/aeb/dossiers/dossier06/textos

Baião, Joana. 2014. “José de Figueiredo, 1871-1937: Ação e Contributos no Panorama Historiográfico, Museológico e Patrimonialista em Portugal.” Tese de doutoramento em História da Arte, especialidade em Museologia e Património Artístico, Universidade Nova de Lisboa.

Bethencourt, Francisco. 1999. “A Memória da Expansão.” In História da Expansão Portuguesa: Último Império e Recentramento (1930-1998), dir. por Francisco Bethencourt, e Kirti Chaudhuri, vol. 5, 442-480. [Lisboa]: Círculo de Leitores.

Campos, Alexandra. 2007. "Nuvens Douradas e Paisagens Habitadas: A Arte Namban e a sua Circulação entre a Ásia e a América: Japão, China e Nova-Espanha (c. 1550-c. 1700).” Tese de doutoramento em História da Arte, Universidade Nova de Lisboa.

Chartier, Roger. 1988. A História Cultural: Entre Práticas e Representações. Tradução de Maria Manuela Galhardo. Lisboa: Difel.

Fernandes, Maria Amélia Bizarro Leitão. 2001. "A Exposição de Arte Portuguesa em Londres 1955-1956: ‘A Personalidade Artística do País'.” Dissertação de mestrado em Arte, Património e Restauro, Universidade de Lisboa, vol. 1.

Ferreira, Maria Emília de Oliveira. 2010. "Lisboa em Festa: A Exposição Retrospectiva de Arte Ornamental Portuguesa e Espanhola, 1882. Antecedentes e Materialização.” Tese de doutoramento em História da Arte Contemporânea, Universidade Nova de Lisboa.

Figueiredo, José de (textos). 1931. L'Art Portugais de l'Époque des Grandes Découvertes au XX Siècle. Paris: MM. Gauthier-Villars.

Figueiredo, José de. 1929. Pavilhão de Portugal em Sevilha: Catalogo da Exposição Cultural da Época dos Descobrimentos. [s.l.: s.n.].

Gomes, Maria Manuela David, dir. 1964 (20 de Agosto). "Página Feminina: A obra a que mais completamente me entreguei foi, sem dúvida, a «Arte Indo-Portuguesa» agora em vias de publicação. Afirmou-nos a Dr. a Maria Madalena de Cagigal e Silva conservadora do Museu de Arte Popular, em Lisboa." Notícias de Setúbal (Ano 3) 121: 2 e 5.

Gomes, Marques, e Joaquim de Vasconcelos. 1883. Exposição Districtal de Aveiro em 1882: Reliquias da Arte Nacional. Aveiro: Gremio Moderno.

Guia Oficial da Exposição Portuguesa em Sevilha. 1929. Lisboa: Comissariado Geral da Exposição Portuguesa em Sevilha. 
Leandro, Sandra. 1997. “A Exposição Retrospectiva de Arte Ornamental Portugueza e Hespanhola 1882: A Encenação de um Espaço.” Dissertação de mestrado em História da Arte, Universidade Nova de Lisboa.

Martins, Fernando. 1998. “A Política Externa do Estado Novo, o Ultramar e a ONU: Uma Doutrina Histórico-jurídica (1955-68).” Penélope 18: 189-206.

Pinto, Carla Alferes. 2014. “A Colecção de Arte Colonial do Patriarcado de Lisboa: Proposta de Estudo e Musealização.” Tese de doutoramento em História da Arte, especialidade em Museologia e Património Histórico, Universidade Nova de Lisboa.

Pinto, Carla Alferes. 2015. "Exposições Oitocentistas fora de Portas e o Contributo dos Objectos Coloniais para a Criação Imaginal do Império Português." Revista Portuguesa de História 46: 263-279.

Roque, Ricardo. 2001. Antropologia e Império: Fonseca Cardoso e a Expedição à Índia em 1895. Lisboa: Imprensa de Ciências Sociais.

Santos, Reinaldo dos. 1954. "A Índia Portuguesa e as Artes Decorativas. Belas-Artes.” Revista e Boletim da Academia Nacional de Belas Artes 2. ․ série 7: 3-16.

Silva, Maria Madalena de Cagigal e. 1966 (18 de Setembro). Parecer. Fundação Calouste Gulbenkian, Biblioteca de Arte, Lisboa. Arquivo COOP. Museu de Arte Sacra da Ilha de Moçambique: processo n. ${ }^{\circ}$ M184/93.

Silva, Maria Madalena de Cagigal e. 1966. A Arte Indo-Portuguesa. Lisboa: Edições Excelsior.

Silva, Maria Madalena de Cagigal e. 1985. “A História e as Relações Artísticas entre Portugal e a Índia.” In II Seminário Internacional de História Indo-Portuguesa: Actas, 373-393. Lisboa: Instituto de Investigação Científica e Tropical, Centro de Estudos de História e Cartografia Antiga.

Viterbo, Sousa. 1883. Exposição d'Arte Ornamental: Notas ao Catalogo. Lisboa: Imprensa Nacional.

\section{NOTAS}

1. Sobre as biografias dos dois técnicos ver Pinto (2014, anexo, 28-52).

\section{RESUMOS}

Em 1966 saiu o livro A Arte Indo-Portuguesa, da autoria de Madalena de Cagigal e Silva (1920-1984). Surgido num contexto de afirmação nacionalista face aos acontecimentos políticos e diplomáticos que circunstanciaram a sua publicação, a reconfiguração do indo-português em categoria artística foi o corolário de um processo de afirmação de Portugal através da narrativa que associava a ideia da "heroica gesta descobridora dos Portugueses" aos objetos artísticos. A classificação de objetos artísticos como indo-portugueses surgira no âmbito da realização da exposição Special Loan Exhibition of Spanish and Portuguese Ornamental Art (1881) no South Kensington Museum em Londres. Recebida, utilizada e criticada em Portugal, a adjetivação étnica manteve-se ancorada nas artes decorativas até ser alargada à escultura, no contexto da 
realização de uma exposição no Museu Nacional de Arte Antiga (1947). O indo-português, largamente dominante quer quanto ao número de peças quer quanto à extensão temporal e territorial que abarcava, foi desde cedo associado aos programas expositivos e museológicos que iam construindo a narrativa da "arte portuguesa", ainda que produzida em contexto nãoeuropeu, contribuindo, a par com outros objetos, para a consolidação de uma ideia de excecionalidade e primazia histórica e identitária nos territórios transoceânicos da Índia e de África, e que se prolongou bem para além da década de 1960. Neste artigo procura-se reconstruir o percurso de aceitação e afirmação do indo-português no contexto do trabalho desenvolvido pelas equipas dos museus nacionais, concomitantemente com a análise do discurso e dos objetos selecionados para a programação das exposições internacionais que tinham por pano de fundo a representação de Portugal num contexto de afirmação política.

The book A Arte Indo-Portuguesa [Indo-Portuguese Art] by Madalena de Cagigal e Silva (1920-1984) was released in 1966. Having appeared in a context of Portuguese national sentiment due to political and diplomatic events that lead to its release, the reconfiguration of the IndoPortuguese into an artistic category was the corollary of Portugal's process of affirmation through a narrative that associated the idea of "the heroic deeds of Portuguese discoveries" to artistic objects. Artistic objects were first classified as Indo-Portuguese in 1881 in an exhibition entitled Special Loan Exhibition of Spanish and Portuguese Ornamental Art (1881) held in London at the South Kensington Museum. Having been brought to Portugal, further used, and criticized the ethnic adjectivisation continued to be associated to the decorative arts until its use was expanded to sculpture, in an exhibition at the Museu Nacional de Arte Antiga (Lisbon) in 1947. Widely dominant both in terms of the number of items and of the time and space it covered, Indo-Portuguese was associated from very early on with the exhibition and museum programmes that built the narrative of a "Portuguese art", even if produced in a non-European context. Along with other objects, the Indo-Portuguese ones, contributed to the consolidation of an idea of exceptionality, a sense of historical and identity precedent in transoceanic territories of India and Africa, lasting well beyond the 1960s. The aim in this paper was to rebuild the process of acceptance and affirmation of the Indo-Portuguese in the context of the work developed by national museums, and at the same time analyze the discourse and objects selected for international exhibitions, which had as background the political and artistic representation of Portugal abroad.

\section{ÍNDICE}

Palabras claves: indo-portuguese art, colonial discourse, international exhibition, Madalena de Cagigal e Silva, Museu Nacional de Arte Antiga

Palavras-chave: arte indo-portuguesa, discurso colonial, exposição internacional, Madalena de Cagigal e Silva, Museu Nacional de Arte Antiga

\section{AUTOR}

\section{CARLA ALFERES PINTO}

Investigadora do Centro de História d'Aquém e d'Além-Mar (CHAM), unidade de investigação da Faculdade de Ciências Sociais da Universidade Nova - Universidade dos Açores. Doutorada em História da Arte, especialidade em Museologia e Património Artístico pela Universidade Nova de Lisboa, com tese sobre A Colecção de Arte Colonial do Patriarcado de Lisboa: Proposta de Estudo e Musealização. Nos últimos anos tem-se dedicado ao estudo do desenvolvimento das relações 
artísticas entre Portugal e a Índia no período moderno, à análise de questões de género relacionadas com a encomenda, a produção e a apropriação de objetos artísticos, e à problematização da recepção e representação do indo-português nos museus nacionais. carla.alferes.pinto@gmail.com 